\title{
Are pseudo-patient studies justified?
}

\section{Author's abstract}

\begin{abstract}
Pseudo-patient studies are studies in which a medical sociologist or anthropologist masquerades as a patient. Medical treatment is sought without revealing that the 'patient' is really a covert research worker. When access has thus been gained to a medical setting - typically a hospital ward - social interaction between medical staff and patients is then observed over a period of days or weeks. Important studies have been carried out in this way of psychiatric treatment and of the care of the terminally-ill. Is the use of the method justified? What ethical problems does its use raise? How do the undoubted advantages of the approach compare with the clear drawbacks and objections which can be made to its use?
\end{abstract}

Observational studies conducted in medical settings by social scientists may be carried out in a variety of ways. One dimension of choice is the extent to which the researcher reveals his identity, and his purposes, to those whom he is studying. In adopting a research role, there is a continuum from openness to secrecy, from an overt identification as a research scientist to a covert presence as a pseudo-patient. This paper examines the ethical and methodological arguments for and against such pseudo-patient studies.

In a pseudo-patient study a person enters a medical setting by adopting the role of a patient, not in order to receive therapy but in order covertly to observe the treatment process and the broader medical and social setting within which it occurs. D L Rosenhan's classic study, 'On being sane in insane places' ( $\mathrm{I}$ ) is an example.

This study involved sending eight pseudo-patients to mental hospitals in different parts of the United States. On arrival, they feigned symptoms of hearing voices, which they reported as being often unclear but which seemed to say 'empty', 'hollow' and 'thud'. Immediately on admission, the pseudo-patients ceased simulating any symptoms of abnormality, and thereafter behaved 'normally'. All except one patient was admitted with a diagnosis of schizophrenia, and when released, after periods varying from seven to 52 days (with an average of 19 days), the diagnosis on release was schizophrenia 'in remission'.

The purpose of conducting the research was to examine the process of psychiatric diagnosis and the effect of this diagnosis upon the pseudo-patient's treatment in hospital. Rosenhan argued that such research could only be done covertly, by feigning the patient role, since observations of the diagnostic process as an outside observer would be tainted by 'reactivity', and the presence of the observer would lead to changes in behaviour of patient and medical personnel. The existence of such measurement effects is welldocumented in both natural and social science.

Most observational field research in medical sociology and anthropology is not done using covert methods. Usually the role of researcher is assumed more or less overtly, and those being studied know that they have a social scientist among them. To what extent is it justifiable to conceal the real identity of the investigator and the fact that research is being undertaken? It may seem self-evident that such behaviour, involving as it does invasion of privacy and gross deception, is manifestly unethical and ought not to be undertaken. Nevertheless such covert studies have yielded original and novel insights into the treatment process and have advanced the frontiers of knowledge.

Rosenhan's psychiatric study was widely noticed upon publication. In $\mathbf{R}$ W Buckingham's covert Canadian study of alternative methods of treating terminal cancer patients (2), he spent two periods of four days as a pseudo-patient, the first in a general surgical ward and the second on a palliative care ward specially designed to meet the known needs of dying patients and their families. His results showed that staff and families spent more time with patients in the palliative care ward, and that the surgical care ward did not provide means of coping with distress and offering adequate comfort. Support for dying patients came from other patients, from the patients' own families, from volunteers and student nurses, as much as from nursing staff or physicians. In particular, the inappropriateness of doctors travelling in groups, avoiding eye contact with the patient and not speaking to the patient by name was shown for the treatment of terminally-ill cancer patients.

Buckingham concludes that 'active treatment wards . . . do not offer an optimal environment for the dying. There is a need for comfort, both physical and mental, for others to see them as individuals rather than as 
hosts for their disease, and for someone to breach the loneliness and help them come to terms with the end' (3). This attempt to study the quality of medical life for a certain type of patient was made possible through Buckingham's willingness to enter hospital as a pseudo-patient and undergo the rigours which this involved. But was it a justifiable method to use?

There is a lively, continuing debate among social scientists, particularly sociologists and anthropologists, about the merits of covert observational research in studying groups such as social deviants, religious sects or political parties, centres of decisionmaking and power in large organisations, or voluntary associations (4). In several contexts, including the medical, there are situations where the presence of the researcher as a true participant provides an inside view' of the setting being studied. Accounts by doctors of their own experience of illness and medical treatment have an unusual interest and importance (5).

A recent collection by a group of medical sociologists (6) provides fresh insights into illness, through accounts of their own illnesses from professionals whose work involves studying medicine. R Jobling, for example, provides an analysis of his experience of suffering from psoriasis and the treatment regimes to which he was subjected. S Macintyre and D Oldman discuss how they cope with migraine. In such accounts, however, the authors are real patients, suffering from real conditions, under the care of a physician because they need medical treatment. What of the social scientist who enters a medical setting under the guise of a patient in order to do research?

\section{The merits of pseudo-patient studies}

Several arguments have been advanced in favour of the use of pseudo-patient studies. The first, and most important, is that they are a means of gaining new knowledge not otherwise available to the social scientist. William Caudill, an American anthropologist, believed this when he undertook a pioneering study 30 years ago (7). While holding a research post at Yale Medical School in I950 he took part in a study of interpersonal relationships among psychiatric patients.

It was decided that Caudill would enter the mental hospital associated with the medical school in the guise of a patient. He was admitted to the less disturbed ward of the hospital, and on being assigned to one of the psychiatrists, he was treated as an in-patient there for a period of two months. He lived on the ward, took part in the daily routine and interacted with the other patients as if he were one of them. After the first week, Caudill had going-out privileges each afternoon which enabled him to leave the ward for a few hours each day to write up his material. Neither the other patients nor the medical staff with whom he was in daily contact knew that he was a social science researcher. His status as a pseudo-patient was a secret known only to two senior medical personnel (8). In reflecting later on his experience, Caudill (like Rosenhan and Buckingham) thought that he had gathered data which would not otherwise have been accessible; in his case on how patients communicated with each other, on what 'time' meant for the patients, and on a sense of what hospital life was like.

A second argument in favour of pseudo-patient studies is their naturalism. The use of researchers whose identities are not known means that the research situation remains true to life, and is not distorted by the presence of (identified) social scientists, whose presence may in turn influence the behaviour of others in that setting. The problem of 'reactivity' is a besetting one in social research. Any means by which one can make the observer more unobtrusive will, it is argued, yield more reliable and valid data (9). Particularly in medical settings where assessments and judgments are being made about patients, the possibility of the investigator covertly appearing as a patient rules out the major source of reactivity he or she would constitute if present as an extraneous and identified observer.

Thirdly, it is also argued that the quality of data from such covert studies is superior. Caudill reported that his covert study 'provided a rich body of data concerning many problems, hitherto only incompletely recognised, which were faced by the patients as a social group in their life on the ward' (I0). Rosenhan maintains that though concealment was distasteful, it was a necessary first step to studying the process of psychiatric diagnosis. 'Without concealment, there would have been no way to know how valid these experiences (as pseudo-patients) were; nor was there any way of knowing whether whatever detections occurred were a tribute to the diagnostic acumen of the staff or to the hospital's rumour network' (I I).

A fourth argument draws parallels with muckraking politicians: and investigative journalists. Medical systems which operate on a fee-per-item-of-treatment basis, with the fee being then reclaimed, in whole or in part, from the state or an insurance company, are particularly liable to financial abuse. In France, journalists presented themselves covertly to doctors with identical symptoms, and observed the variations in treatment provided, thereby exposing abuses of the medical insurance system. In the United States, Senator Frank Moss, chairman of the US Senate SubCommittee on Long-term Care, revealed in 1976 that he had acquired a Medicaid card and had secretly visited a medical centre, sending aides and Capitol Hill policemen covertly to a further 120 'Medicaid Mills' in New York City.

These visits revealed widespread fraud, through the use of unnecessary tests, extensive referrals and a number of prescriptions (12). Such abuses would not come to light without such undercover inquiries.

For American sociologist Jack D Douglas, such undercover work provides a model for social research practice. Writing in the aftermath of Watergate, and enormously impressed by the achievements of Washington Post journalists Woodward and Bernstein 
(13), Douglas argues that the world is permeated to such an extent by deception and manipulation that covert methods are fully justified on the part of the social scientist, and moreover rather innocuous in their effects (14).

A final justification for pseudo-patient studies points to the widespread use of deception of certain kinds in medical practice. The use of misleading statements and even outright lies cannot be ruled out in certain transactions between physician and patient, as Sissela Bok has shown (15). Patients are not always given full information about their condition, and in some cases (such as terminally-ill cancer patients) deception may be used to conceal the gravity of the patient's condition.

In medical experimentation, deception is an integral part of the research design. 'Double-blind' trials and placebo treatment conceal from both researchers and patients what treatment the patients are actually receiving, or whether the patients receive any meaningful treatment at all. Admittedly, both researchers and patients know that they are participating in an experiment, but they may be actively misled as to what the experiment is about. Compared to these forms of deception, that used in pseudo-patient studies is rather mild.

Moreover, pseudo-patient studies do something to redress the balance in favour of the patient, in that it is the medical staff who are most likely to be deceived. In Rosenhan's study of psychiatric diagnosis, his eight subjects at first feared discovery and exposure. They therefore made notes secretly of their observations on the ward. However, as time passed there seemed to be no reason to maintain this secrecy, and they began to take notes openly on the ward. This led many fellowpatients to suspect that they were not patients but observers. 'You're not crazy. You're a journalist, or a professor. You're checking up on the hospital' (I6).

No medical staff, however, voiced suspicions about the true purposes of the pseudo-patients in taking notes, and in three cases notes recorded in their file suggested that the writing was pathological. 'Patient engages in writing behaviour' (I7) was a comment on one who was never questioned about what he was doing by the medical staff. The use of deception thus results, at worst, in the biter being bit.

\section{The de-merits of pseudo-patient studies}

Against these arguments favouring the use of pseudopatient studies may be set several powerful objections which are based on the belief that not only are these methods unethical they also tend to produce data which lack authenticity.

\section{HARM TO THOSE BEING STUDIED}

The doctor-patient relationship is one based upon mutual trust and confidence. It is personal and confidential (I8). To act as a pseudo-patient flagrantly breaches this fiduciary relationship. Other medical staff and fellow-patients are also involved. In Caudill's covert study, when he and his supervisor Fritz Redlich subsequently revealed what had been going on to those at the hospital, the medical personnel were angered.

There can be doubt [Redlich later wrote] that the effect of the clandestine observation on the professional staff of the hospital was severe. They felt spied upon. They were particularly angry over what they considered was the betrayal of [Caudill's] psychotherapist. This good man himself actually never complained, but maintained that he had learned something. . . . The nurses were particularly angry, because they thought that Caudill was not only deceitful but did not like them (I9).

The use of deception by-passes the manifold problems of gaining the trust of those whom one is observing in social-science field research, but the sense of betrayal which those studied experience when the identity of the researcher becomes known (as it must if results are published) is correspondingly much greater.

Covert studies also breach informed consent requirements, which were first developed in response to the abuse of medical research in Nazi Germany, and which are an integral part of ethical practice in medical experimentation (20). Those being studied by covert observations are kept ignorant that they are being studied. The voluntary consent of the human subject is completely lacking. It is true that, where the identity of the researcher is known, there are still considerable problems in obtaining informed consent in ethnographic work (2I). Does one walk around a hospital ward asking everyone one meets to sign a consent form, for instance? Nevertheless, this does not justify the violation of the principle which is involved in secret observation.

\section{RISK TO THE INVESTIGATOR}

If the pseudo-patient is mistaken for a real patient and treated accordingly, the investigator may suffer actual harm. It is not accidental that the majority of pseudopatient studies have been in the area of psychiatry, where observable physical symptoms are less frequent than for most other conditions. Even so, patients will receive treatment that they may not desire. In the Rosenhan study, patients were routinely given medication. In total, the eight pseudo-patients were given 2100 pills including Elavil, Stelazine, Compazine and Thorazine, while in hospital. Only two of these pills were actually swallowed. The remainder were either pocketed or flushed down the toilet. That this was possible, Rosenhan attributes to the depersonalisation of patients by nursing staff (22). Nevertheless, pseudo-patients run the risk of having to receive medication which they neither need nor want. In an Australian study involving hospitalisation of research subjects, Winkler reports that Valium and Mogadon were given to help pseudo-patients sleep, against their will (23). Moreover, the fact that as a rule they did not 
receive medication singled out the observers from the other patients who said to them: 'You can't be sick. There can't be anything wrong with you'.

Another problem in psychiatric studies is that nonvoluntary pseudo-patients may find themselves confined in hospital against their will when faced with, for example, family emergencies at home. Rosenhan experienced this problem in his study, though he had not at first anticipated it. Stress to the pseudo-patient may be the result.

In feigning physical symptoms, greater risks to the investigator are run. In the Buckingham study, he himself was admitted in the guise of a patient with terminal pancreatic carcinoma. Prior to admission, he underwent supra-clavicular incision (indicative of cervical lymph node biopsy) and ultraviolet irradiation to produce erythema over the epigastrium and spine (suggesting radiation therapy to the pancreas) (24). This was to convince medical staff of the genuineness of his condition. During his stay in hospital he had occasion to refuse a nasogastric tube. One reason that his identity as a pseudo-patient was known to six staff in the entire hospital (25) was to ensure that he was not operated upon during his stay, in the belief that he was a real patient.

\section{HARM TO THE INVESTIGATOR}

Such risks may be minimised by advance planning. What can not be avoided is the possibility of physical or psychological harm to the investigator as a result of taking the pseudo-patient role. Like the plastic surgery undergone in Sullivan's pseudo-enlistment study of the US army (26), in Buckingham's Canadian study he underwent the minor surgery and irradiation already referred to. In addition, his body was made to look the part by 'puncture sites from intravenous infusion needles on the hands and arms, a ro-kg weight loss induced by a 6-month diet, patchy beard alopecia related to the stress of preparation, and abstinence of several days from washing or shaving' (27).

After the first 48 hours, Buckingham began to experience pain and sickness for much of the time. On the second ward, the palliative care ward, he became even weaker and more exhausted. 'He was anorexic and routinely refused food. He felt ill. It took all his energy to take a shower. He sat exhausted in a chair. He experienced increasing pain, a constant ache in his left leg together with numbness, and restless nights during which family members of other patients commented sympathetically on his "moaning and groaning". $M$ himself [Buckingham] was unaware of this nocturnal behaviour' (28).

The processes involved here are similar to, but more intense than, those experienced by hypochondriac trainee doctors who diagnose in themselves illnesses which they are studying in others (29). The observer identifies with those whom he is observing, and takes on some of the characteristics of the observed.

Psychological effects are even more common than physical effects. In Rosenhan's study all subjects experienced stress, and all but one wanted to be discharged immediately after admission. Buckingham's anxiety level was evident in psychosomatic symptoms before the field-work began and was evident to his collaborators during the nine days on the ward. D K Reynolds assumed an imaginary identity and obtained admission to a US Veterans' Administration Hospital, by claiming (falsely) that he had recently attempted suicide on hearing that his wife had left him for another man. So successful was his simulation of depression that after admission he came to feel genuinely depressed himself, and at one point staged a fake suicide attempt. He also attributed constipation during his hospital stay to the effects of these assumed depressed feelings (30).

In William Caudill's case, the documentation is fullest. In addition to Caudill himself, two independent observers confirm that the stresses were so great that all three doubted whether it would be advisable to repeat such a study. His supervisor, F C Redlich, wrote in 1973:

There can be no doubt that Caudill found the concealed study stressful. At the end for a short time I believe he lost his objectivity as a participant observer, and almost became a participant, a patient. . . . Although Caudill felt there was too much fuss made over concealment in his own study as well as in later studies - such as in Milgram's work - he suffered from it (3I).

Another view is provided by Caudill's friend George de Vos:

My memory shifts to another meeting with Bill some three years later. It was 3.00 am and Bill was expressing a great deal of inner turmoil concerning the unusual research role he had been playing at Yale (in the covert study). . . . The strain on Bill between his role as an objective observer and his human sensitivity to people who were deceived by his dissembling developed into a very severe personal and career crisis. The subsequent publications from this research revealed little of this ordeal. It was a learning experience for all who participated, and the lesson was the need for caution about the effects of research on the doers as well as the subjects (32).

There is thus clear evidence that acting as a pseudopatient can be, at least in the short-term, harmful to the investigator.

LEGAL AND ETHICAL PROBLEMS IN AN INSTITUTIONAL CONTEXT

The management of pseudo-patient studies poses complex legal and ethical problems for the institutions in which they are conducted. In the Canadian cancer study, the legal liability of the hospital for anything happening on its premises had to be anticipated. In Rosenhan's study, provision had to be made to release pseudo-patients from hospital should they wish to be released and be unable to achieve it themselves. In the 
course of the research, as appreciation of the possible difficulties grew, 'a writ of habeas corpus was prepared for each of the entering pseudo-patients and an attorney was kept "on call" during every hospitalisation' (33).

In other cases, the admission of a pseudo-patient was done in the knowledge of at least one member of the senior medical staff of the hospital. In Buckingham's study, six knew, in Caudill's two, including his supervisor. This desire to let a few colleagues into the secret (in order to safeguard the position of the pseudopatient, and to facilitate the research) does, however, create problems of confidence among professional colleagues. Thus, when Redlich revealed to the staff members that Caudill's study had just been concluded, the majority were outraged. One of his close associates called it sordid at an open meeting. Several colleagues were particularly critical of the deception of Caudill's psychiatrist, which they saw as degrading psychotherapy (34). The revelation of the research thus, for a period at least, diminished trust between professional colleagues. In addition to loss of trust with patients, the use of the covert approach accentuated problems among the researcher's own peer group.

In Buckingham's study, those in the know were four senior doctors and two administrators. There was thus a potentially explosive situation between these senior staff and the housemen, nurses, orderlies and volunteers on the wards who were not in the researcher's confidence. The structural distribution of knowledge in the project was potentially a source of tension. Those in charge of the study considered that the major problems of secrecy arose less from leaks during the project than from 'the socioprofessional position of those who knew the secret' when the secret was finally made public. Reactions of the staff to this revelation are not recorded (35).

\section{THE QUALITY OF DATA IN COVERT STUDIES}

One of the most substantial objections to the use of covert methods is that the use of such methods affects the quality of the data gathered. Far from giving access to otherwise unobtainable data, it tends to yield less reliable and valid results than would overt observation.

In the first place, to what extent can the pseudopatient successfully adopt the role of the true patient and be accepted as such by all in the setting? In Rosenhan's study, there was clear evidence in a large minority of the cases that the other patients (though never the medical staff) realised that the subjects were not real patients. Subjects in Winkler's Australian study were identified as not ill because they read a book on the ward. Note-taking in particular identifies the researcher as a researcher and draws attention to his differentness from other patients.

The feigning of convincing symptoms as a pseudopatient is also difficult. Buckingham found it particularly difficult to imitate the passivity and inactivity of very sick cancer patients.
A few days after admission, increased activity began to assert itself and the researcher's physical mobility on the ward became more and more atypical of the normal patient role. In the palliative care ward where most of the patients were bedridden and some even unable to speak, this atypical mobility was accentuated and was accompanied by increasing demands on staff for special attention. The investigator himself justified the more active behaviour as a necessary change in the research design. He felt that only with increased mobility could he observe and interact with patients and with their families, who were permitted free access to the bedside. From the outside observer's vantage point the increasing emotional load of these demands was more obvious, and the growing dissimilarity between the investigator and other patients in the unit was equally blatant (36).

Clearly, Buckingham was behaving in ways different from other patients, with (unknown) consequences for his own perceptions of the situation, and for his interactions with medical staff, fellow-patients and the families of patients. He admits, for example, that he became emotionally involved with some members of the families of other patients, writing poems for them and expressing feelings of grief (37).

F Redlich's final judgment on Caudill's study was that the emotional involvement of the covert observer detracted from objectivity:

Our most important expectation was to obtain maximally objective and detailed information by a scientifically trained observer. To our surprise we found that Caudill did not remain objective. He became a member of the patient society and identified with the patients. Temporarily, Caudill really became a 'patient'. . . . He developed considerable antagonism against the nurses, with whom he got into repeated quarrels, and even fights. . . . His most moving, though not necessarily his most objective accounts, depicted, almost with passion, the society of patients as a society of underdogs (38).

Caudill himself subsequently undertook a second, overt, observational study in the same hospital (after a period of patient turnover) (39). He concluded, comparing the data collected on the first and second studies, that the second, overt, approach was superior. Both provided rich insights into the workings of a hospital ward and interaction among patients. But the second study yielded a wider range of data over which it was possible to exercise a greater degree of control. He was more satisfied, emotionally and intellectually, with the second study (40).

A comparison of Caudill's two studies suggests not only the distorting effect of playing the covert role, but also that the need to adopt the covert role in the first place may be considerably exaggerated. The ethical dilemmas posed by the use of the method may be false ones, in the sense that the original objectives may be achieved by other means. A comparison of pseudopatient studies of psychiatric hospitals with overt 
studies of hospitals such as that of Stanton and Schwarz (4I) suggests that this is indeed the case. Experience in other areas such as the study of crime or politics shows that much data can be obtained by overt methods, even from settings hitherto thought to be inaccessible (42).

\section{Conclusion}

The use of pseudo-patient studies as a means of investigating the patient's experience of medicine is suspect but not to be ruled out altogether. Murray and Buckingham conclude that role-playing and covert participant observation should be used with great care in medical anthropology.

When a choice is available, other methods of investigation are preferable; role-playing should be restricted to only those field situations in which no other method of investigation can reasonably be expected to yield satisfactory data (43).

Several social scientists who have used this method subsequently concluded that its use was best avoided in the future. That of Caudill has already been cited, and Redlich concurred:

We have learned not to take it for granted that research always benefits human-kind. If it actually or potentially harms rather than helps individuals and populations, we insist today to protect such individuals and populations and forego the search for truth (44).

Though the risks are smaller in social science than in biomedical research, the problems of freedom, privacy and human dignity remain subtle. In the light of these considerations Redlich (writing in the year of Watergate) states that he would not today have undertaken the concealed study (45).

The broader ethical calculus to weigh up the rights and wrongs of such studies is difficult. Should this sort of study be discarded as a dramatic but unconvincing use of methods of dubious ethical validity, or does it offer insights not otherwise available, particularly in understanding relationships between people? (46). The arguments reviewed earlier in this paper are on the whole stronger against such studies than in their favour. Nevertheless, in an Australian study of general practitioners' approaches to patients with psychiatric symptoms, Owen and Winkler urge the use of such methods to provide a consumer perspective on health care, and to provide feedback on the experience of medical treatment which is unavailable from other sources (47).

Bok considers that there is justification for the monitoring elements (rather than the mere acquisition of new knowledge) provided by pseudo-patient studies. The existence of such monitoring ensures that standards are checked and possibly maintained. Relationships between physicians and their patients are not equivalent to private sexual or religious behaviour, and ought to be open to public scrutiny (48).
The debate will continue, illuminated by the occasional empirical study using the covert approach. The ethical and methodological questions raised by pseudo-patient studies are likely to defy definitive solution and remain dilemmas requiring the exercise of moral choice.

\section{References}

(I) Rosenhan D L. On being sane in insane places. Science 19 January 1973; 179: 250-258, reprinted in Bulmer $M$, ed. Social research ethics. London: Macmillan, and New York, Holmes and Meier, 1982: 15-37.

(2) Buckingham $\mathrm{R} \mathrm{W}$, et al. Living with the dying: use of the technique of participant observation. Canadian medical association journal December 18, 1976; II5: I2I I-I 15.

(3) See reference (2) p 1215 .

(4) Homan R. The ethics of covert methods. British journal of sociology 1980; 3I: 46-59; Bulmer M. Comment on 'The ethics of covert methods'. British journal of socio$\log y$ 1980; 31: 59-65; Dingwall R. Ethics and ethnography. Sociological review 1980; 28: 871-891. For more general discussion of these and related issues, see Diener E, Crandall R. Ethics in social and behavioural research. Chicago: University of Chicago Press, 1978; Barnes J A. Who should know what? Social science, privacy and ethics. Cambridge University Press, 1979, and reference (I).

(5) Greene R, ed. Sick doctors. London: Heinemann, 1971 .

(6) Davis A, Horobin G, eds. Medical encounters: the experience of illness and treatment. London: Croom Helm, 1977.

(7) Caudill W, Redlich F C, Gilmore H R, Brody E B. Social structure and interaction processes on a psychiatric ward. American journal of orthopsychiatry 1952; 22: 314-334.

(8) Redlich F C. Ethical aspects of clinical observation of behaviour. Foumal of nervous and mental disease 1973 ; 157: 5: 313-319.

(9) Webb E J, Campbell D T, Schwarz R D, Sechrest L. Unobtrusive measures: non-reactive research in the social sciences. Chicago: Rand McNally, I966; ch I.

(I0) See reference (7) p 315.

(II) See reference (I) p 258, footnote 9.

(12) Bok S. Lying: moral choice in public and private life. Hassocks, Sussex: Harvester, 1978, 198-199.

(13) Bernstein C, Woodward B. All the president's men. London: Secker \& Warburg, 1974.

(14) Douglas J D. Investigative social research. Beverley Hills: Sage, 1976.

(15) See reference (12) ch Xv.

(I6) See reference (I) p 252.

(17) See reference (I) p 253.

(18) Thompson I E. The nature of confidentiality. Foumal of medical ethics 1979; 5: 57-64.

(19) See reference (8) p 316.

(20) Annas G J, et al. Informed consent to human experimentation: the subject's dilemma. Cambridge, Mass: Ballinger, 1977.

(21) Wax M L. On field workers and those exposed to fieldwork. Human organisation 1977; 36: 32 I-328; Duster T, et al. Fieldwork and the protection of human subjects. The American sociologist 1979; I4: 136-142.

(22) See reference (I) p 256. 
(23) Winkler R C. Research into mental health practice using pseudo-patients. Medical journal of Australia September 14, 1974; 6I, no 2: 399-403.

(24) See reference (2) p I 2 I I.

(25) Murray W B, Buckingham R B. Implications of participant observation in medical studies. Canadian medical association journal December 18, 1976; I15: I $187-1$ I 90.

(26) Sullivan M A, et al. Participant observation as employed in a military training program. American sociological review 1958; 23: 660-667.

(27) See reference (2) pp I I I I-I2I2.

(28) See reference (2) p 1212.

(29) See reference (6) pp I7-3I.

(30) Reynolds D K, Farkerow N L. Suicide: inside and out. Berkeley: University of California Press, 1976 , reviewed in Sutherland S. The case of the pseudo-patient. Times Literary Supplement 1977 February 4: 125.

(3I) See reference (8) p 315.

(32) de Vos G, Vogel E. Achievement, culture and personality: the case of William Caudill. Fournal of neroous and mental disease 1973; $157 ; 4$ : 232-239.
(33) See reference (I) p 258, footnote 8.

(34) See reference (8) p 315.

(35) See reference (25) p i 188.

(36) See reference (25) p i 188.

(37) See reference (25) p i I 88.

(38) See reference (8) pp 314-315.

(39) Research reported in Caudill W. The psychiatric hospital as a small society. Cambridge, Mass: Harvard University Press, 1958.

(40) See reference (39) pp xiv-xvi.

(4I) Stanton A H, Schwartz M S. The mental hospital. New York: Basic Books, I954: 426-448.

(42) See reference (I) $230 \mathrm{ff}$.

(43) See reference (25) p i 190.

(44) See reference (8) p 319.

(45) See reference (8) pp 319-320.

(46) Involved in dying. Lancet 1977; April 2: 736.

(47) Owen A, Winkler R. General practitioners and psychosocial problems: an evaluation using pseudopatients. Medical journal of Australia 1974; 6I; 2: 393-398.

(48) See reference (12) pp 200-20r. 